\title{
Antifibrinolytic Therapy in Complex Spine Surgery. A Case-Control Study Comparing Aprotinin and Tranexamic Acid.
}

\author{
Maria J. COLOMINA, MD; JOAN BAGÓ, MD; XAVI VIDAL, MD; LIDIA MORA, MD; FERRAN PELLISÉ, MD
}

\section{ahstract}

Full article available online at OrthoSuperSite.com/view.asp? rlD=00000

A case-control study was performed to determine the impact of aprotinin or tranexamic acid use on reducing intraoperative blood loss and transfusion needs in complex spine surgery. Sixty-nine patients undergoing complex spine surgery received aprotinin or tranexamic acid. The aprotinin group contained 30 patients ( 8 men and 22 women) and the tranexamic acid group 39 patients (11 men and 28 women). The following variables were recorded: duration of surgery, number of levels fused, intraoperative and total blood loss, and number of blood units transfused (autologous and allogenic). In addition, various parameters related to blood loss in this type of surgery were calculated. The groups differed with regard to duration of surgery (aprotinin $662 \mathrm{~min}$ vs tranexamic acid $448 \mathrm{~min}, P<.001$ ) and number of levels fused (aprotinin $11.2 \mathrm{vs}$ tranexamic acid 7.6, $P=.004)$. There were no significant differences in intraoperative blood loss (aprotinin $2118 \mathrm{~mL}$ vs tranexamic acid $1608 \mathrm{~mL}, P=.066$ ) or total blood loss (aprotinin $3312 \mathrm{~mL}$ vs tranexamic acid $2627 \mathrm{~mL}, P=.056$ ). Statistical differences were found for the number of autologous blood units transfused (aprotinin 2.2 vs tranexamic acid $1.3 P=.047$ ) and total units transfused (aprotinin 4.1 vs tranexamic acid 2.6, $P=.008$ ). Blood loss per hour of surgery, transfused units per level fused and transfused units per hour of surgery were similar in the 2 groups. Significant differences were found for intraoperative blood loss per fusion level (aprotinin $228 \mathrm{~mL}$ vs tranexamic acid 428, $P=.025$ ) and total blood loss per fusion level (aprotinin $360 \mathrm{~mL}$ vs tranexamic acid $638 \mathrm{~mL}, P=.01$ ). Analysis of the applied geometric mean showed that aprotinin reduced total blood loss by $16.4 \%$ and total number of blood units transfused by $12.4 \%$ as compared to tranexamic acid, although statistical significance was not reached. The type of antifibrinolytic used did not have a significant impact on the main outcome variables of the study.

Drs Colomina and Mora are from the Department of Anesthesia, Drs Bagó and Pellise are from the Department of Spine Surgery, and Dr Vidal is from the Department of Pharmacotherapy, Hospital Universitario Vall d'Hebron, Area de Traumatología, Barcelona, Spain.

FINANCIAL DISCLOSURE:

Correspondence should be addressed to: Maria J. Colomina, MD, Department of Anesthesia, Passeig Vall d'hebron 119 - 129, 08035 - Barcelona, Spain. 
$\mathrm{C}$ omplex spine surgery is associated with a considerable loss of blood during the procedure. ${ }^{1-3}$ This is a result of several characteristics inherent to the surgery, such as extensive bone decortication, the release of particles during bone manipulation (eg, thromboplastin), fluid therapy-induced dilutional coagulopathy, and the microthrombi present in transfusion blood. ${ }^{1,4-6}$ Much concern has focussed on avoiding blood transfusion in this type of surgery and several measures have been adopted to achieve this. Among them, the use of antifibrinolytic drugs may be effective. ${ }^{7-10}$

Antifibrinolytic agents have been mainly used in heart surgery to reduce intraoperative bleeding and transfusion requirements. ${ }^{11}$ In addition, they have been introduced in several major orthopedic surgical procedures. Two recent metaanalyses by Shiga et al ${ }^{12}$ and Zufferey et $\mathrm{al}^{13}$ have confirmed the efficacy of aprotinin and tranexamic acid versus placebo on intraoperative blood loss and transfusion needs in various orthopedic surgery procedures. A Cochrane Collaboration Review ${ }^{14}$ has gathered evidence that Aprotinin and tranexamic acid reduce perioperative transfusion needs and decrease intraoperative blood loss in both heart surgery and orthopedic surgery. The review recommended that comparative studies between these 2 agents be performed to determine whether there are significant differences in their performance, instead of new placebo-controlled studies. Nevertheless, no published articles with these characteristics have emerged and there are no comparative studies on the use of these drugs in spine surgery.

This study evaluated the effectiveness of aprotinin and tranexamic acid in the management of intraoperative blood loss and transfusion requirements in patients undergoing complex surgery of the spine.

\section{Material And Methods}

This is a retrospective study of 2 series of patients scheduled for complex spine surgery who received different antifibrinolytics during surgery. From 2001 to 2003 intraoperative antifibrinolytic agents were used in 69 cases. The patients for whom this treatment was decided were 10 to 75 years, with a body weight $>30 \mathrm{~kg}$ and a body mass index $<30 \mathrm{~kg} / \mathrm{m}^{2}$, scheduled for complex spine surgery. Patients with spinal tumors or acute trauma often receive antifibrinolytic treatment as well, but were not included in the analysis. The use of antifibrinolytics was not considered indicated in patients with a history of allergy or hypersensitivity to the agents used, those under treatment with drugs that might interfere with coagulation (eg, acetylsalicylic acid, nonsteroid anti-inflammatory drugs, and anticoagulants), history of frequent bleeding, platelet count $<150,000 / \mathrm{mm}^{3}$, abnormal prothrombin time or activated partial thromboplastin time, a history of a thromboembolic episode or family history of thromboembolism, or plasma creatinine values $>1.3$ $\mathrm{mg} / \mathrm{dL}$.

\section{Groups}

The antifibrinolytic drugs under study were aprotinin and tranexamic acid. The decision of which of these drugs to use was made by the attending anesthesiologist.

Tranexamic Acid Group. The tranexamic acid group was comprised of 39 patients (28 women and 11 men) with a mean age of 35.1 years (SD 18.2). The diagnoses included adult scoliosis in 16 patients, neuromuscular scoliosis in 7, congenital scoliosis in 1, and degenerative lumbosacral disease in 15 . The surgical interventions were posterior instrumented fusion in 28 patients, anterior instrumented fusion in 1 , and anterior plus posterior instrumented fusion in 10 . In 12 cases, $360^{\circ}$ fusion was performed using a posterior lumbar interbody approach (PLIF): one-level PLIF in 7 cases, two-level PLIF in 4 , and three-level PLIF in 1. In 2 additional cases, extensive laminectomy was done to treat severe central stenosis (one- level decompression in 1 case and twolevel decompression in another patient). Tranexamic acid (Amchafibrin 500 mg; Rottapharm S.L., 5-mL vials) was administered at a bolus dose of $10 \mathrm{mg} / \mathrm{kg}$ during 20 minutes before starting surgery, and at $2 \mathrm{mg} / \mathrm{kg} / \mathrm{hour}$ in continuous perfusion up to completion of the procedure.

Aprotinin Group. The aprotinin group contained 30 patients (22 women and 8 men) with a mean age of 41.4 years (SD 17.0). The diagnoses included adult scoliosis in 17 patients, neuromuscular scoliosis in 8 , degenerative lumbosacral disease in 2, and posttraumatic kyphosis in 3. The surgical intervention consisted of posterior instrumented fusion in 8 patients and anterior plus posterior instrumented fusion in 22 patients. To correct sagittal plane imbalance, pedicle subtraction osteotomy at L3 was done in one case and multiple Smith-Petersen osteotomies in another case. One patient received a two-level PLIF, four-level canal stenosis decompression was done in another patient, and one-level decompression in another. Aprotinin (Trasylol; Bayer AG, $50-\mathrm{mL}$ vials, $70 \mathrm{mg}$ of aprotinin, equivalent to 500,000 kallikrein inhibiting units [KIU]) and sodium chloride $0.9 \%$ as isotonic solution was administered as a bolus dose of $240 \mathrm{mg} / \mathrm{m}^{2}$ (approximately 2.106 KIU) during 20 minutes at 30 minutes before the first surgical incision and following administration of a recommended test dose of $5000 \mathrm{KIU}$ ( $1 \mathrm{~mL}$ of the solution). After administration of the initial bolus, continuous perfusion at $56 \mathrm{mg} / \mathrm{m}^{2}$ (approximately 500,000 KIU/hour) was given to completion of surgery.

The anesthesia technique included propofol, fentanyl, midazolam, and rocuronium bromide in all cases. Mechanical ventilation was set at a minute-volume equivalent to $10 \mathrm{~mL} / \mathrm{kg}$ and a respiratory rate of 10 to 12 breaths per minute. We used $100 \%$ oxygen for preoxigenation and $50 \%$ oxygen for the remainder of the intervention. Maintenance anesthesia consisted of continuous perfusion of fentanyl 
at $3-5 \mu \mathrm{g} / \mathrm{kg} /$ hour, rocuronium bromide at $0.02 \mathrm{mg} / \mathrm{kg} /$ hour, and desflurane as the hypnotic agent.

Various parameters that might have an influence on intraoperative blood loss were controlled during surgery. Patients were maintained at an esophageal temperature of $>35^{\circ} \mathrm{C}$, mean blood pressure 55 to $70 \mathrm{~mm} \mathrm{Hg}, \mathrm{PaCO} 234$ to $40 \mathrm{~mm} \mathrm{Hg}$, and fluid support to maintain the urinary output at $>0.5 \mathrm{~mL} / \mathrm{kg} /$ hour. Following surgery, all patients were monitored for at least 24 hours in the recovery unit and were attended by the same surgery-anesthesia team up to hospital discharge.

The following variables were recorded for each patient: 1) anthropometric characteristics, including weight, height, and body mass index (BMI); 2) surgery characteristics, including duration of the procedure, number of levels fused, and days hospitalized; 3) intraoperative blood loss, measured by aspiration and by weighing the sponges and gauze used on a digital scale; 4) postoperative blood loss, measured as the volume through the drains during the first 48 hours. Total blood loss was calculated as the sum of the intraoperative loss plus the postoperative loss at 48 hours following surgery; (5) number of units of predonated autologous blood and allogenic blood transfused. The transfusion trigger was established at $8 \mathrm{~g} / \mathrm{dL}$. The following were also monitored: prothrombin time (PT), activated partial thromboplastin time (APTT), fibrinogen, and platelets. Administration of freshfrozen plasma was indicated when the international normalized ratio (INR) was $>1.5$, fibrinogen $<0.5 \mathrm{~g} / \mathrm{dL}$, and platelets $<80.000 / \mathrm{mm}^{3}$, and whenever there was clinical evidence of bleeding; and 6) adverse effects (thrombotic phenomena and allergic reactions) associated with use of the drugs.

Since it is known that perioperative blood loss is related with the characteristics of the surgery (duration and levels fused), ${ }^{1,15,16}$ the following parameters were calculated to facilitate the between-

\begin{tabular}{|c|c|c|c|c|c|}
\hline \multicolumn{6}{|c|}{ Table 1} \\
\hline \multicolumn{6}{|c|}{ Surgery Characteristics } \\
\hline & \multicolumn{2}{|c|}{ APT $(n=30)$} & \multicolumn{2}{|c|}{ TXA $(n=39)$} & \multirow[b]{2}{*}{$P$ value } \\
\hline & Mean & SD & Mean & SD & \\
\hline $\begin{array}{l}\text { Duration of the surgical } \\
\text { intervention (min) }\end{array}$ & 662.3 & 210.6 & 448.4 & 157.2 & $<.001$ \\
\hline No of levels fused & 11.2 & 4.3 & 7.6 & 5.8 & .004 \\
\hline Days of hospitalization & 17.2 & 10.3 & 13.2 & 8.8 & .086 \\
\hline
\end{tabular}

group comparisons: intraoperative blood loss per level fused and total blood loss per level fused (mL/level), intraoperative blood loss per hour of surgery $(\mathrm{mL} / \mathrm{h})$, transfused units per level fused and per hour of surgery.

\section{Statistical Analysis}

The statistical analysis was carried out with SAS, version 9.1. A descriptive analysis of the main variables was performed in the two groups. The comparison of means was done with Student's $t$ test and comparison of percentages with chisquare analysis. To compare the results of the variable total blood loss, values were first submitted to logarithmic transformation to normalize the distribution. Subsequently, multivariate regression analysis was done using total blood loss as the dependent variable and the following as predictive variables: age, sex, duration of surgery, number of fused levels, baseline hemoglobin and hematocrit, and the type of drug received. A second multivariate analysis was performed using total number of units transfused as the dependent variable.

\section{RESULTS}

There were no significant differences between the groups with regard to age (aprotinin 41.4 vs tranexamic acid 35.1), weight (aprotinin $60.9 \mathrm{~kg}$ vs tranexamic acid $61.8 \mathrm{~kg}$ ), height (aprotinin $157 \mathrm{~cm}$ vs. tranexamic acid $160 \mathrm{~cm}$ ), or BMI (aprotinin 24.70 vs tranexamic acid 24.14).
The data related to the surgical intervention are shown in Table 1. In the aprotinin group, values were significantly higher for the duration of surgery $(P<.001)$ and the number of fused levels $(P=.004)$. There were no differences in the duration of hospitalization.

Baseline hemoglobin and hematocrit were similar in the 2 groups (Table 2). There were no significant differences in the intraoperative, postoperative or total blood loss, although it should be noted that total blood loss in the aprotinin group was almost $700 \mathrm{~mL}$ greater than in the tranexamic acid group. Intraoperative blood loss in the aprotinin group was almost $700 \mathrm{~mL}$ greater than in the tranexamic acid group. Intraopertaive blood loss relative to blood volume of each patient was 0.42 (42\%) in the tranexamic acid group and 0.55 (55\%) in the aprotinin group. A larger (although nonsignificant) difference was observed when total blood loss was calculated according to blodd volume: tranexamic acid group 0.69 and aprotinin group 1.46 Postoperative hemoglobin and hematocrit were similar in both groups.

Table 3 depicts the transfusion requirements in the two groups. Aprotinin patients received more autologous blood units and more total units. The various blood loss-related parameters calculated for the groups are shown in Table 4. Intraoperative and total blood loss per fusion level was significantly lower in the aprotinin group than in patients receiving tranexamic acid. There were no differenc- 


\begin{tabular}{|c|c|c|c|c|c|}
\hline \multicolumn{6}{|c|}{ Table 2} \\
\hline \multicolumn{6}{|c|}{ Blood Loss } \\
\hline & \multicolumn{2}{|c|}{ APT $(n=30)$} & \multicolumn{2}{|c|}{ TXA $(n=39)$} & \multirow[b]{2}{*}{$P$ value } \\
\hline & Mean & SD & Mean & SD & \\
\hline $\begin{array}{l}\text { Preoperative hemo- } \\
\text { globin }(\mathrm{g} / \mathrm{dL})\end{array}$ & 12.5 & 1.6 & 13.0 & 1.7 & .165 \\
\hline $\begin{array}{l}\text { Preoperative hema- } \\
\text { tocrit (\%) }\end{array}$ & 36.5 & 4.4 & 38.1 & 4.8 & .161 \\
\hline $\begin{array}{l}\text { Intraoperative blood } \\
\text { loss (mL) }\end{array}$ & 2118.3 & 1255.8 & 1608.7 & 1012.8 & .066 \\
\hline $\begin{array}{l}\text { Postoperative blood } \\
\text { loss }(\mathrm{mL})\end{array}$ & 1227.2 & 623.5 & 1017.2 & 776.8 & .230 \\
\hline Total blood loss $(\mathrm{mL})$ & 3312.2 & 1523.9 & 2627.2 & 1386.3 & .056 \\
\hline $\begin{array}{l}\text { Postoperative hemo- } \\
\text { globin }(\mathrm{g} / \mathrm{dL})\end{array}$ & 9.9 & 1.1 & 10.3 & 1.1 & .236 \\
\hline $\begin{array}{l}\text { Postoperative hema- } \\
\text { tocrit }(\%)\end{array}$ & 29.9 & 3.4 & 29.8 & 3.0 & .900 \\
\hline
\end{tabular}

\begin{tabular}{|c|c|c|c|}
\hline \multicolumn{4}{|c|}{ Table 3} \\
\hline \multicolumn{4}{|c|}{ Blood Units Transfused } \\
\hline & APT & TXA & $P$ value \\
\hline Patients & 30 & 39 & \\
\hline $\begin{array}{l}\text { Total no. units } \\
\text { transfused }\end{array}$ & $4.1 \pm 2.1$ & $2.6 \pm 2.2$ & .008 \\
\hline $\begin{array}{l}\text { Autologous units } \\
\text { transfused }\end{array}$ & $2.2 \pm 2.1$ & $1.3 \pm 1.5$ & .047 \\
\hline $\begin{array}{l}\text { Allogeneic units } \\
\text { transfused }\end{array}$ & $1.8 \pm 2.6$ & $1.3 \pm 2.3$ & .37 \\
\hline
\end{tabular}

Table 4

\begin{tabular}{|c|c|c|c|}
\hline Ratio & APT & TXA & $P$ value \\
\hline $\begin{array}{l}\text { Intraoperative blood loss/no. of } \\
\text { fused levels (mL per level) }\end{array}$ & $228.5 \pm 187.5$ & $428.1 \pm 494.7$ & .025 \\
\hline $\begin{array}{l}\text { Intraoperative blood loss/ dura- } \\
\text { tion surgical intervention (mL } \\
\text { per hour surgery) }\end{array}$ & $192.5 \pm 81.6$ & $216.7 \pm 118.9$ & .3 \\
\hline $\begin{array}{l}\text { Transfusion units / duration } \\
\text { surgical intervention (mL per } \\
\text { hour surgery) }\end{array}$ & $0.34 \pm 0.75$ & $0.38 \pm 0.36$ & .4 \\
\hline $\begin{array}{l}\text { Transfusion units / no. of fused } \\
\text { levels (mL per level) }\end{array}$ & $0.43 \pm 0.26$ & $0.53 \pm 0.75$ & .4 \\
\hline
\end{tabular}

es between the groups in the intraoperative blood loss per hour of surgery, transfused units per hour of surgery nor transfused units per level fused.

The first multivariate analysis identified sex $(P=.005)$, age $(P=.001)$ and surgery duration $(P<.001)$ as independent variables related with blood loss in spine surgery. Type of antifibrinolytic was not statistically significant $(P=.07)$. According to the multivariate model, the variable surgery duration was the clearly the main predictive factor of total blood loss among the patients in our study. The geometric mean of the variable total blood loss (ie, the mean adjusted by age, sex, and duration of surgery) was $2478 \mathrm{~mL}$ for the aprotinin group and 2972 for the tranexamic acid group, Blood loss was $16.4 \%$ lower (95\% CI , 2.1\%-32\%) in patients receiving aprotinin as compared to those receiving tranexamic acid, although the difference was not statistically significant.

In the second multivariate model, the variables significantly associated with the number of transfused units were age $(P=.013)$ and duration of surgery $(P<.001)$. Again, the type of antifibrinolytic given was not significant $(P=.4)$. The geometric means were 2.85 for the aprotinin group and 3.26 for those receiving tranexamic acid, which represents a relative transfusion reduction of $12.6 \%$ (95\% CI, 21.2\%-36.9\%) in the aprotinin group.

None of the patients in either group experienced complications related with the administration of antifibrinolytic drugs including thromboembolic events, renal insufficiency, cardiac complications or anaphylactic phenomena.

\section{DISCUSSION}

Blood loss is one of the most important complications associated with complex surgery of the spine and has been attributed to the duration of surgery, among other factors. ${ }^{6,16-18}$ Our results provide further support that the length of the intervention is a predictive variable for perioperative blood loss. Other predictive factors found 
in this study include age (the older the patient, the greater the blood loss) and sex (greater bleeding in males), for which the independent impact on blood loss is difficult to explain. Nevertheless, several variables that were not included in the study design (neuromuscular deformity, osteoporosis) may contribute to explaining the differences found.

One of the main objectives in complex spine surgery is to reduce the number of blood units administered. ${ }^{8,16-19}$ Again, surgery duration and sex were independent predictors of transfusion. In contrast, the baseline hemoglobin and hematocrit did not emerge as independent predictive factors, although they are considered major predictors in other types of orthopedic surgeries. ${ }^{5,20}$

Our results suggest that aprotinin is slightly superior to tranexamic acid in reducing blood loss and transfusion requirements in complex spine surgery. Nevertheless, we cannot draw firm conclusions because our study is observational and groups were different in some critical variables such as duration of surgery and number of fused levels. The aprotinin group included patients with conditions that can be labeled "complex deformities." The surgical procedures to treat these conditions usually involve instrumentation of several levels as well as circumferential fusions. The tranexamic acid group included patients undergoing complex surgery for degenerative lumbosacral disease, some with decompression at several levels and PLIF procedures. These differences between the treatment groups explains why bleeding was higher in patients receiving aprotinin $(3312 \mathrm{~mL})$ as compared to the tranexamic acid group $(2627 \mathrm{~mL})$. In addition, a significant difference was found for the total number of units transfused (aprotinin 4.1 vs tranexamic acid 2.6; $P=.008$ ). However, the analysis of the parameters blood loss per fusion level and blood loss per hour of surgery (Table 4) suggests that the differences are not attributable to the type of treatment received, but instead to the fact that the most complex patients (greater number of levels fused, lengthier surgery, and circumferential approach) had been assigned to the aprotinin group. On the contrary, analysis of the geometric mean (i.e., the mean adjusted by age, sex and duration of surgery) indicates that aprotinin use results in a $16.4 \%$ greater reduction in blood loss and a $12.4 \%$ greater decrease in the number of blood units transfused as compared to tranexamic acid. These data suggest that aprotinin administration produces a comparatively larger reduction in operative bleeding and secondarily, a decrease in the number of units transfused.

Despite the growing evidence of the benefits of both aprotinin and tranexamic acid for reducing blood loss and transfusion requirements in spine surgery, there are no studies comparing these treatments. The introduction of antifibrinolytic drugs to control intraoperative bleeding is relatively recent in spine surgery. The first related studies assessed the efficacy of aprotinin or tranexamic acid against placebos. ${ }^{7,9,21-23}$ Urban et al ${ }^{16}$ reported a comparison between aprotinin, epsilon-aminocaproic acid and placebo in a series of adult patients with complex scoliosis and characteristics similar to the patients in the present study. The authors found that intraoperative blood loss and transfusion requirements were significantly lower in patients receiving aprotinin, with no differences between the epsilon-aminocaproic acid and placebo groups. Randomized, double-blind studies comparing aprotinin with a control group and reported by Cole et $\mathrm{al}^{7}$ and Khoshhal et $\mathrm{al}^{9}$ have described the efficacy of aprotinin for reducing intraoperative blood loss in children and adults undergoing surgery for spinal deformity. Lentschener et $\mathrm{al}^{23}$ found a significant decrease in blood loss and number of units transfused as compared to a placebo group in patients treated with lumbosacral fusion.

Other authors have not found these superior results for aprotinin versus placebo.
Amar et $\mathrm{al}^{24}$ reported no differences in surgical bleeding or transfusion needs in a randomized study comparing aprotinin and epsilon-aminocaproic acid versus a placebo in skeletal surgery for neoplastic disease. Nonetheless, the duration of surgery was clearly shorter in these patients as compared to the series of Urban et al ${ }^{16}$ and our patients.

Recent meta-analyses have confirmed the efficacy of tranexamic acid for reducing intraoperative blood loss and transfusion requirements in various orthopedic procedures performed in adult patients, ${ }^{13,25,26}$ as well as in spine surgery. Neilipovitz et $\mathrm{al}^{21}$ found a significant reduction in transfusion needs in a prospective, randomized, controlled study comparing tranexamic acid versus placebo in children and adolescents undergoing scoliosis surgery. Sethna et al ${ }^{22}$ reported a significant decrease in intraoperative blood loss, but no difference in transfusion needs, in a randomized controlled trial comparing tranexamic acid versus placebo in patients undergoing scheduled scoliosis correction.

Our results suggest a small advantage of using aprotinin. The meta-analysis of Zufferey et $\mathrm{al}^{13}$ also points in this direction. However, in an editorial comment on the meta-analysis, Wesikopf ${ }^{27}$ indicated that the difference may have little clinical relevance. In ou study, this reduction would represent saving 0.48 of transfusión units or reducing $529 \mathrm{~mL}$ of blood loss. Moreover, this slight advantage should also be assessed in terms of safety and cost. The safety of aprotinin use is currently under considerable discussion. Recent studies assessing the safety of this agent in cardiac surgery ${ }^{28,29}$ have concluded that the risk of death and complications of severe renal failure are higher in patients undergoing coronary artery bypass graft surgery with aprotinin treatment. Another drawback to the use of this drug is the risk of severe anaphylactic reactions, which have been reported at around $4 \% .{ }^{30}$ In contrast, no problems related with safety have been 
described for tranexamic acid. Lastly, although a comparative cost assessment of these two treatments is beyond the scope of this study, the elevated cost of aprotinin relative to tranexamic acid is well recognized. In fact, Kovesi et $\mathrm{al}^{31}$ have noted that this factor could be one of the main disadvantages for carrying out controlled clinical trials comparing these drugs.

In conclusion, our results show that the duration of the surgical procedure is the main variable having an impact on operative bleeding and transfusion requirements in complex spine surgery. It is likely that aprotinin use results in a greater reduction in operative bleeding than tranexamic acid. Nevertheless, the difference was not statistically significant and its clinical relevance does not seem evident.

\section{REFERENCES}

1. Meert KL, Kannan S, Mooney JF. Predictors of red cell transfusion in children and adolescents undergoing spinal fusion surgery. Spine. 2002; 27:2137-2142.

2. Erstad BL. What is the evidence for using hemostatic agents in surgery? Eur Spine J. 2004; 13:28-33.

3. Kannan S, Meert KL, Mooney JF, HillmanWiseman C, Warrier I. Bleeding and coagulation changes during spinal fusion surgery: a comparison of neuromuscular and idiopathic scoliosis patients. Pediatr Crit Care Med. 2002; 3:364-369.

4. Fox HJ, Thomas CH, Thompson AG. Spinal instrumentation for Duchenne's muscular dystrophy: experience of hypotensive anaesthesia to minimise blood loss. J Pediatr Orthop. 1997; 17:750-753.

5. Nuttall GA, Horlocker TT, Santrach PJ, Oliver WC Jr, Dekutoski MB, Bryant S. Predictors of blood transfusions in spinal instrumentation and fusion surgery. Spine. 2000; 25:596 -601.

6. Weis JC, Betz RR, Clements DH, Balsara RK. Prevalence of perioperative complications after anterior spinal fusion for patients with idiopathic scoliosis. J Spinal Disord. 1997; 10:371-375.

7. Cole JW, Murray DJ, Snider RJ, Bassett GS, Bridwell KH, Lenke LG. Aprotinin reduces blood loss during spinal surgery in children. Spine. 2003; 28:2482-2485.

8. Neilipovitz DT. Tranexamic acid for major spinal surgery. Eur Spine J. 2004; 13:62-65.

9. Khoshhal K, Mukhtar I, Clark P, Jarvis J, Letts M, Splinter W. Efficacy of aprotinin in reducing blood loss in spinal fusion for idiopathic scoliosis. J Pediatr Orthop. 2003; 23:661-664.

10. Kokoszka A, Kuflik P, Bitan F, Casden A Neuwirth M. Evidence-based review of the role of aprotinin in blood conservation during orthopaedic surgery. J Bone Joint Surg Am. 2005; 87:1129-1136.

11. Royston D, Bidstrup BP, Taylor KM, Sapsford RN. Effect of aprotinin on need for blood transfusion after repeat open-heart surgery. Lancet. 1987; 2:1289-1291.

12. Shiga $T$, Wajima $Z$, Inoue $T$, Sakamoto $A$. Aprotinin in major orthopedic surgery: a systematic review of randomized controlled trials. Anesth Analg. 2005;101:1602-1607.

13. Zufferey P, Merquiol F, Laporte S, et al. Do antifibrinolytics reduce allogeneic blood transfusion in orthopedic surgery? Anesthesiology. 2006;105:1034-1046.

14. Henry DA, Moxey AJ, Carless PA, et al. Antifibrinolytic use for minimising perioperative allogeneic blood transfusion. Cochrane Database Syst Rev. 2001; CD001886.

15. Nuttall GA, Horlocker TT, Santrach PJ, Oliver WC Jr, Dekutoski MB, Bryant S. Use of the surgical blood order equation in spinal instrumentation and fusion surgery. Spine. 2000; 25:602-605.

16. Urban MK, Beckman J, Gordon M, Urquhart $\mathrm{B}$, Boachie-Adjei O. The efficacy of antifibrinolytics in the reduction of blood loss during complex adult reconstructive spine surgery. Spine. 2001; 26:1152-1156.

17. Rizzi PE, Winter RB, Lonstein JE, Denis F, Perra JH. Adult spinal deformity and respiratory failure. Surgical results in 35 patients. Spine. 1997; 22:2517-2530.

18. Lisander B, Jonsson R, Nordwall A. Combination of blood-saving methods decreases homologous blood requirements in scoliosis surgery. Anaesth Intensive Care. 1996; 24:555-558.

19. Samama CM. A direct antifibrinolytic agent in major orthopedic surgery. Orthopedics. 2004; 27:675-680

20. Salido JA, Marin LA, Gomez LA, Zorrilla P Martinez C. Preoperative hemoglobin levels and the need for transfusion after prosthetic hip and knee surgery: analysis of predictive factors. J Bone Joint Surg Am. 2002; 84:216220.

21. Neilipovitz DT, Murto K, Hall L, Barrowman NJ, Splinter WM. A randomized trial of tranexamic acid to reduce blood transfusion for scoliosis surgery. Anesth Analg. 2001; 93:82-87.

22. Sethna NF, Zurakowski D, Brustowicz RM, Bacsik J, Sullivan LJ, Shapiro F. Tranexamic acid reduces intraoperative blood loss in pediatric patients undergoing scoliosis surgery. Anesthesiology. 2005; 102:727-732.

23. Lentschener C, Cottin P, Bouaziz H, Mer- cier FJ, Wolf M, Aljabi Y, Boyer-Neumann C, Benhamou D. Reduction of blood loss and transfusion requirement by aprotinin in posterior lumbar spine fusion. Anesth Analg. 1999; 89:590-597.

24. Amar D, Grant FM, Zhang H, Boland PJ, Leung DH, Healey JA. Antifibrinolytic therapy and perioperative blood loss in cancer patients undergoing major orthopedic surgery. Anesthesiology. 2003; 98:337-342.

25. Cid J, Lozano M. Tranexamic acid reduces allogeneic red cell transfusions in patients undergoing total knee arthroplasty: results of a meta-analysis of randomized controlled trials. Transfusion. 2005; 45:1302-1307.

26. Ho $\mathrm{KM}$, Ismail $\mathrm{H}$. Use of intravenous tranexamic acid to reduce allogeneic blood transfusion in total hip and knee arthroplasty: a meta-analysis. Anaesth Intensive Care. 2003; 31:529-537.

27. Weiskopf RB. If you prick us, do we not bleed? Anesthesiology. 2006; 105:873-876.

28. Mangano DT, Tudor IC, Dietzel C. The risk associated with aprotinin in cardiac surgery. N Engl J Med. 2006; 354:353-365.

29. Mangano DT, Miao Y, Vuylsteke A, et al Mortality associated with aprotinin during 5 years following coronary artery bypass graft surgery. JAMA. 2007; 297:471-479.

30. Llau JV, Garcia-Perez ML. Increased safety in the administration of aprotinin: need for a test-dose. Anesth Analg. 2000; 90:770-771.

31. Kovesi T, Royston D. Pharmacological approaches to reducing allogeneic blood exposure. Vox Sang. 2003; 84:2-10. 